\title{
Assessment of Long-term Groundwater Abstraction and Forest Growth Impacts on Watershed Hydrology Using SWAT
}

\author{
Wonjin Kim ${ }^{1}$, Jinuk Kim ${ }^{1}$, Soyoung Woo ${ }^{1}$, Jiwan Lee ${ }^{1}$, Sehoon Kim ${ }^{1}$, and Seong Joon Kim ${ }^{1}$ \\ ${ }^{1}$ Konkuk University
}

May 18, 2021

\begin{abstract}
This study used Soil and Water Assessment Tool (SWAT) to investigate the impacts of groundwater abstraction and forest growth on the watershed hydrology of Geum River basin (9,645.5 km2), South Korea. Groundwater abstraction (GA) and forest growth (FG) data from 1976 to 2015 (1980s;1976 1985, 1990s; 1986 1995, 2000s; 1996 2005, 2010s;2006 2015) were prepared with 10-year interval as SWAT input data, respectively. SWAT was calibrated $\left(2006^{\sim} 2015\right)$ using daily observation data from two multipurpose dams and three multifunction weirs. The dam and weir calibration result showed coefficient of determination (R2) of $0.78,0.81$, Nash-Sutcliffe efficiency (NSE) of 0.79, 0.76, root mean square error (RMSE) of $1.96 \mathrm{~mm} / \mathrm{day}, 0.55 \mathrm{~mm} / \mathrm{day}$, and PBIAS of $-5.48 \%, 8.56 \%$, respectively. The SWAT ran at each decade using corresponding GA and FG information under the same weather condition of the 2010s to evaluate the impact of GA and FG on hydrologic cycle. Influenced by both GA and FG, the streamflow at the watershed outlet showed the decrease of $1.3 \%$ (10.1 mm/year), $4.4 \%$ (34.2 mm/year), and $7.8 \%$ (60.3 mm/year) in the $1990 \mathrm{~s}$, the $2000 \mathrm{~s}$, and the $2010 \mathrm{~s}$, respectively. The hydrologic response of surface runoff, lateral flow, groundwater flow, and soil moisture showed decreasing trend while evapotranspiration and groundwater recharge showed increasing trend. GA imposed bigger influence on the spatial and temporal loss of streamflow than FG. Especially, it was discovered that the agricultural water use from groundwater was the most influential factor that has decreased total runoff in the target watershed for the last four decades.
\end{abstract}

\section{Assessment of Long-term Groundwater Abstraction and Forest Growth Impacts on Watershed Hydrology Using SWAT}

Running head: Long-term Groundwater Abstraction and Forest Growth Impact

Wonjin Kim ${ }^{1}$, Jinuk Kim ${ }^{1}$, Jiwan Lee $^{1}$, Soyoung Woo ${ }^{1}$, Sehoon Kim ${ }^{1}$, and Seongjoon Kim ${ }^{2}$

${ }^{1}$ Department of Civil, Environmental and Plant Engineering, Graduate School, Konkuk University, Seoul 05029, South Korea

${ }^{2}$ Division of Civil and Environmental Engineering, College of Engineering, Konkuk University, Seoul 05029, South Korea

\section{Corresponding Author}

Name: Seongjoon Kim

Mailing Address: Room \#237, D-dong, College of Engineering, Konkuk University, Neungdongro 120, Seoul, South Korea

Email address:kimsj@konkuk.ac.kr

\section{AUTHORSHIP}


Wonjin Kim: Conceptualization, Methodology, Writing-Original Draft Preparation, Jinuk Kim: Visualization, Jiwan Lee: Investigation. Soyoung Woo: Data Curation, Sehoon Kim: Validation, Seongjoon Kim: Supervision, Editing.

\section{CONFLICT OF INTERESTS}

The authors declare that they have no conflict of interest

\section{Abstract}

This study used Soil and Water Assessment Tool (SWAT) to investigate the impacts of groundwater abstraction and forest growth on the watershed hydrology of Geum River basin $\left(9,645.5 \mathrm{~km}^{2}\right)$, South Korea. Groundwater abstraction (GA) and forest growth (FG) data from 1976 to 2015 (1980s;1976 1985, 1990s; 1986 1995, 2000s; 1996 2005, 2010s;2006 2015) were prepared with 10-year interval as SWAT input data, respectively. SWAT was calibrated $\left(2006^{\sim} 2015\right)$ using daily observation data from two multipurpose dams and three multifunction weirs. The dam and weir calibration result showed coefficient of determination $\left(\mathrm{R}^{2}\right)$ of $0.78,0.81$, Nash-Sutcliffe efficiency (NSE) of 0.79, 0.76, root mean square error (RMSE) of $1.96 \mathrm{~mm} /$ day, $0.55 \mathrm{~mm} /$ day, and PBIAS of $-5.48 \%, 8.56 \%$, respectively. The SWAT ran at each decade using corresponding GA and FG information under the same weather condition of the 2010s to evaluate the impact of GA and FG on hydrologic cycle. Influenced by both GA and FG, the streamflow at the watershed outlet showed the decrease of $1.3 \%$ (10.1 mm/year), $4.4 \%$ (34.2 mm/year), and $7.8 \%$ (60.3 mm/year) in the $1990 \mathrm{~s}$, the $2000 \mathrm{~s}$, and the 2010s, respectively. The hydrologic response of surface runoff, lateral flow, groundwater flow, and soil moisture showed decreasing trend while evapotranspiration and groundwater recharge showed increasing trend. GA imposed bigger influence on the spatial and temporal loss of streamflow than FG. Especially, it was discovered that the agricultural water use from groundwater was the most influential factor that has decreased total runoff in the target watershed for the last four decades.

Keywords: Stream drying phenomena, Groundwater abstraction, Forest growth, SWAT.

\section{INTRODUCTION}

Stream drying phenomena, which are often defined as long-term declines in water levels caused by sustained factors, are key issues associated with groundwater use, and they define the reduction in streamflow rates caused by various factors that are hydraulically related to a given stream. With watershed development and increasing groundwater use, studies evaluating these phenomena have recently gained interest. However, there are many difficulties in investigating continuous stream drying and studying the phenomena from a quantitative perspective. The difficulties come from complex factors that are not clearly understood or defined (Jung \& Kim, 2017) and the lack of hydrological data in small rivers where stream drying usually occurs. Jung, Lee, Lee and Kim (2019) considered stream drying phenomena by applying five different factors, groundwater abstraction, afforestation, watershed development, road development, and soil erosion, and ranked their contribution rates to the loss of runoff. The results demonstrated that groundwater abstraction and forest growth had a relatively higher influence on stream drying than did other factors.

Increased population numbers and increased amounts of harvest trigger increases in water demand. Although the demand can be fulfilled using surface water sources such as lakes, rivers, and reservoirs, heavy rain in South Korea is concentrated in Summer; thus, the water demand in other seasons cannot be met from surface water stored in the sources. Therefore, groundwater is often used solely or with surface water to satisfy insufficient surface water supplies. However, when groundwater abstraction exceeds groundwater recharge for a long time, groundwater depletion can occur (Gleeson et al., 2010), and the lowering of groundwater levels can result in serious effects on natural streamflow and related ecosystems (Kirk \& Herbert, 2002). Many studies have tried to determine the hydrological impacts of groundwater abstraction. Wen and Chen (2006) explored the spatial distribution of streamflow trends for and climatic impacts on the watershed and concentrated on the analysis of streamflow residuals from gauging stations to determine the decrease in baseflow caused by groundwater withdrawals. Kim, Lee, Lee and Won (2012) quantified the streamflow depletion from groundwater pumping for the target watershed. Jung and Kim (2017) identified stream drying 
by tracing the flow decrease from cell-based hydrological routing under different land use and groundwater use conditions.

Forest growth changes the net loading of streamflow by intercepting precipitation, controlling the rate of evapotranspiration, and extracting groundwater from vegetation roots. Thus, quantifying the influences of forest growth on watershed hydrology is crucial for planning forest or land management and adaptation strategies for watershed ecosystem sustainability. The relationship between forest growth and water cycle in watersheds has been studied for a long time, and several studies have demonstrated that forest changes can significantly affect streamflow and watershed hydrology by altering its pattern, magnitude, frequency, and quality. Mackay and Band (1997) showed that the canopy distribution has significant effects on simulated hydrological outputs where evaporative demand exceeds available water. Birkinshaw, Bathurst, and Robinson (2014) made full use of the unique 45-year dataset over the entire cycle from the original upland grassland vegetation through plowing the catchment and through forest growth up to mature trees. The results showed clear changes in the nonstationary nature of the catchment, with an annual increase in intercepted evaporation and a decrease in discharge as the trees grew. Yue and Hashino (2004) assessed the impact of forest growth on the streamflow of the basin using statistical trend analysis. The results demonstrated that forest growth was responsible for the decrease in all regimes and that the increase in evapotranspiration due to forest growth resulted in a decrease in both total runoff and low flow.

This study applied the periodic changes in groundwater abstraction and forest growth to the hydrological model and quantified their influences on watershed hydrology. It is believed that considering the two effective stream drying factors and defining their relative contributions to watershed hydrology will improve previous studies that did not consider them together. The study was performed using the Soil and Water Assessment Tool (SWAT), and the applicability of SWAT in simulating watershed scale hydrology and water quality has been proven around the world (Shi et al., 2011; Zhang, Srinivasan, Arnold, Izaurralde \& Bosch, 2011; Luo, Arnold, Allen \& Chen, 2012; Lee, Shin \& Jung, 2014; Lee, Jung, Kim \& Kim, 2019; Woo, Jung, Lee \& Kim, 2019). SWAT was calibrated to verify its applicability in simulating the watershed hydrology of the Geum River basin. The calibrated SWAT simulated the watershed hydrology under three scenarios, and the results were analyzed to determine the contributions of water loss factors to the hydrologic variations.

\section{DATA AND METHODS}

\subsection{Study Area}

The Geum River is one of the four national and major rivers in South Korea, located in the Midwest part of the country with a basin area of $9,912 \mathrm{~km}^{2}$ and a river length of $397.79 \mathrm{~km}$. The rivers in South Korea are generally classified into three groups: rivers of state, local level 1, and local level 2. Currently, there are 11 rivers of state with a total of $397.79 \mathrm{~km}, 20$ rivers of local level 1 with a total of $358.70 \mathrm{~km}$, and 460 rivers of local level 2 with a total of $3000.87 \mathrm{~km}$ in the Geum River basin. However, among 460 rivers of local revel 2, 39 rivers are experiencing stream drying phenomena and their total length is $25 \mathrm{~km}$ (Korea Water Resources Corporation, 2009).

The Geum River originates from southwestern South Korea, where Yongdam Dam (YDD) is located. It passes through Daecheong Dam (DCD), Sejong Weir (SJW), Gongju Weir (GJW) and Baekjae Weir (BJW) and discharges into the West Sea. The five hydraulic structures support five million people living in the region and are crucial since most hydrologic inflows arriving during the flood season are stored in the facilities and used throughout the dry season.

The dominant soil textures of the study are sandy loam and loam which occupies $58 \%$ and $24 \%$. The predominant land use in the basin is forest that accounts for $62 \%\left(5,980 \mathrm{~km}^{2}\right)$. Cultivated cropland, composed of paddy fields and upland crops, is mainly distributed in lowland fertile areas covering $26 \%\left(2,508 \mathrm{~km}^{2}\right)$. The remaining areas are filled with urban, grassland, and bare fields that each cover $3-5 \%$ of the whole catchment.

[Insert Figure 1] 


\subsection{Soil and Water Assessment Tool (SWAT)}

SWAT is a watershed hydrology model developed to quantify the impact of land management practices. The model operates by dividing the watershed into subbasins, with each subbasins being connected to stream channels. Subbasins are further divided into hydrological response units (HRUs), which are portions of a subbasin that possess unique land use, management, and soil attributes. The simulation of the hydrological cycle is based on the water balance equation:

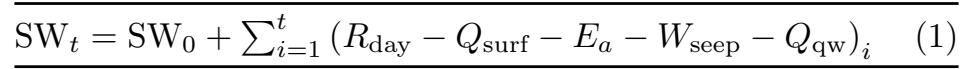

The water balance for dams or floodgates considers inflow, outflow, precipitation, evapotranspiration, and seepage. The equation is expressed as follows:

$$
\begin{aligned}
& \overline{V=V_{\text {stored }}+V_{\text {flow in }}-V_{\text {flow out }}+V_{\text {pcp }}-V_{\text {evap }}-V_{\text {seep }}} \quad(2) \\
& \hline
\end{aligned}
$$

where $V$ is the water storage in the reservoir at the end of each day; $V_{\text {stored }}$ is the volume of water stored in the reservoir at the beginning of a day; $V_{\text {flow in }}$ and $V_{\text {flow out }}$ are the volumes of water entering and flowing out of the reservoir throughout a day, respectively; and $V_{p c p}, V_{\text {evap }}$, and $V_{\text {seep }}$ are the volumes of precipitation falling into the reservoir, the water removed by evaporation and the water lost by seepage, respectively.

\subsubsection{Groundwater Abstraction}

Consumptive water use is a management tool in SWAT that removes water from a basin. Water removed for consumptive use is designed to be lost from the system. SWAT allows water to be removed from a shallow aquifer, deep aquifer, reach, or pond within any subbasin in the watershed selectively. Consumptive water use varies from month to month. For each month in the year, an average daily volume of water is removed from the source and is specified (Neitsch, Arnold, Kiniry \& Williams, 2005). A shallow aquifer composed of sand, gravel, and clay is distributed throughout South Korea. The aquifer has good porosity with adequate nutrients for cultivation so that it is mainly used as a major source of groundwater (Park, Lee, Koo \& Kim, 2016). Thus, monthly groundwater use was applied to be removed from a shallow aquifer using consumptive water use tool in SWAT.

The National Groundwater Information Center updates annual groundwater use report which provides groundwater abstraction (GA) information with three types: agricultural, industrial, and domestic. Based on the report, the annual use data in study area from 1976 to 2015 were collected and they were monthly averaged in 10-year periods (the 1980s, the 1990s, the 2000s, the 2010s) so that SWAT could simulate GA scenario periodically. Figure 2 illustrated the monthly and annual groundwater use of the Geum River basin corresponding to the four decades. The annual groundwater use has gradually increased since the 1980s, appeared to have $107.6 \%$ increase rate in the 2010 s compared with the 1980 s. The monthly use was highly concentrated in June, July, and August. This pattern coincided with the precipitation trend of South Korea, in which most rainfall occurs in Summer. The groundwater use database has been constructed in subbasin unit for every decade. Figure 3 shows the spatial increment of groundwater use in every decade compared with the 1980s. Middle and Northern part of the target catchment showed relatively higher increase of groundwater use.

[Insert Figure 2]

[Insert Figure 3]

\subsubsection{Forest Growth}

In the initial period of plant growth, canopy height and leaf area development are controlled by the optimal leaf area development curve: 
\begin{tabular}{ll}
$\mathrm{fr}_{\mathrm{LAImx}}=\frac{\operatorname{fr}_{\mathrm{PHU}}}{\operatorname{fr}_{\mathrm{PHU}}+\exp \left(l_{1}-l_{2} \bullet \mathrm{fr}_{\mathrm{PHU}}\right)}$ & $(3)$ \\
\hline
\end{tabular}

where $f_{\mathrm{LAImx}}$ is the fraction of the plant's maximum leaf area index (LAI) corresponding to a given fraction of potential heat units for the plant, $\mathrm{fr}_{\mathrm{PHU}}$ is the fraction of potential heat units accumulated for the plant on a given day in the growing season, and $l_{1}$ and $l_{2}$ are shape coefficients.

The shape coefficients are calculated by solving Equation 4 and 5 using two known points $\left(\mathrm{fr}_{L A I, 1}, \mathrm{fr}_{P H U, 1}\right)$ and $\left(\mathrm{fr}_{L A I, 2}, \mathrm{fr}_{P H U, 2}\right)$ :

\begin{tabular}{|c|c|c|c|}
\hline$l_{1}=\ln$ & {$\left[\frac{\mathrm{fr}_{P H U, 1}}{\operatorname{fr}_{L A I, 1}}-\operatorname{fr}_{P H U, 1}\right]$} & $+l_{2} \bullet \mathrm{fr}_{P H U, 1}$ & $(4)$ \\
\hline$l_{2}=\underline{(\ln }$ & $\begin{array}{c}{\left[\frac{\mathrm{fr}_{P H U, 1}}{\mathrm{fr}_{L A I, 1}}-\mathrm{fr}_{P H U, 1}\right]-l r} \\
\mathrm{fr}_{P H U}-\mathrm{fr}_{2}\end{array}$ & $\left.n\left[\frac{\mathrm{fr}_{P H U, 2}}{\mathrm{fr}_{L A I, 2}}-\mathrm{fr}_{P H U, 2}\right]\right)$ & $(5)$ \\
\hline
\end{tabular}

where $l_{1}$ is the first shape coefficient, $l_{2}$ is the second shape coefficient, $f_{P H U, 1}$ is the fraction of the growing season corresponding to the $1^{\text {st }}$ point on the optimal leaf area development curve, $\mathrm{fr}_{L A I, 1}$ is the fraction of the maximum plant LAI corresponding to the $1^{\text {st }}$ point on the optimal leaf area development curve, $\operatorname{fr}_{P H U, 2}$ is the fraction of the growing season corresponding to the $2^{\text {nd }}$ point on the optimal leaf area development curve, and $\mathrm{fr}_{L A I, 2}$ is the fraction of the maximum plant LAI corresponding to the $2^{\text {nd }}$ point on the optimal leaf area development curve.

For tree stands, the canopy height varies from year to year rather than from day to day:

$$
\overline{h_{c}=h_{c, \max } \bullet\left(\frac{\mathrm{yr}_{\text {cur }}}{\mathrm{yr}_{\text {fulldev }}}\right) \quad(6)}
$$

where $h_{c}$ is the canopy height for a given day $(\mathrm{m}), h_{c, \text { max }}$ is the plant's maximum canopy height $(\mathrm{m}), \mathrm{yr}_{\text {cur }}$ is the age of the tress (years), and $\mathrm{yr}_{\text {fulldev }}$ is the number of years for the tree species to reach full development (years). Once plant growth reaches the maximum canopy height, $h_{c}$ remains the same until the plant is killed. However, the kill operation of tree is not activated in the model, and forest height will maintain its maximum value when forest growth stops (Neitsch et al., 2005).

Forest information used to represent periodic forest growth (FG) condition are forest height and LAI. Canopy height data was collected from forest type maps of Korea Forest Service where provides overall forest information in South Korea. LAI was retrieved from the Land Processes Distributed Active Archive Center (LP DAAC) where supports monthly LAI (MOD15A2) measured at a 1,000 m spatial resolution. However, the retrieval has the limitation that LAI data starts from 2000. Therefore, LAI data from 1976 to 1999 were regressed using the relationship between canopy height and LAI. The regression applied power function which shows the must proper curve fitting of canopy height and LAI (Yongwei, Xinsheng, Fang \& Jinyan, 2013). Collected forest data were averaged and divided into a 10-year interval which is coincident with the interval used for GA database.

The leaf area development curve (Figure 4. (a)) and canopy height development curve (Figure 4. (b)) are determined by six parameters, two known points on the optimal leaf area development curve $\left(\mathrm{fr}_{\mathrm{LAI}}, \mathrm{fr}_{\mathrm{PHU}}\right)$, the maximum LAI (BLAI), the fraction of the growing season at which senescence becomes the dominant growth process (DLAI), the maximum canopy height (CHTMX), and the number of years for the tree species to reach full development $\left(\mathrm{yr}_{\text {fulldev }}\right)$. Since averaged values were retrieved and applied to SWAT, leaf area and canopy height development curves were devised by fitting the six parameters to maintain the LAI and canopy height at their periodic averages while simulating the watershed hydrology (Figure 4).

[Insert Figure 4] 


\section{RESULTS}

\subsection{SWAT Calibration}

SWAT was calibrated to verify its applicability of simulating the watershed hydrology of the Geum River basin. The SWAT calibration was performed from 2006 to 2015 while 4 years (2002 2005) served as the warm-up period. Calibration and validation were conducted from 2006 to 2010 and from 2011 to 2015, respectively. The calibration was carried out in daily time steps based on the observed inflow data at five monitoring points, two multipurpose dams (YDD, DCD) and three multifunction weirs (SJW, GJW, BJW). Besides, GA and FG condition of the 2010s were input to the SWAT during the calibration.

SWAT parameters adjusted to calibrate the model are the SCS curve number, Manning's "n" value, soil evaporation compensation factor, groundwater delay time, threshold depth for the return flow in the shallow aquifer, baseflow recession constant, saturated hydraulic conductivity, snowfall temperature, snow melt base temperature, and hydraulic structure sources (Table 1). Default value was used for other parameters that are not mentioned in Table 1.

[Insert Table 1]

The model performance was evaluated by coefficient of determination $\left(\mathrm{R}^{2}\right)$, Nash-Sutcliffe efficiency (NSE), root mean square error (RMSE), and percent bias (PBIAS). The annual evaluation results were averaged for the calibration, validation, and the total period. Table 2 presented the statistical summary of dam calibrations. The calibration result of the total period achieved $\mathrm{R}^{2}$ values of 0.73 and 0.82 , NSE values of 0.81 and 0.77 , RMSE values of $2.35 \mathrm{~mm} /$ day and $1.57 \mathrm{~mm} /$ day, and PBIAS values of $-2.51 \%$ and $-8.44 \%$ for YDD and DCD, respectively. Table 3 shows the statistical summary of weir calibrations. The calibration result of the total period showed $\mathrm{R}^{2}$ values of $0.79,0.81$, and 0.82 ; NSE values of $0.75,0,75$ and 0.77 ; RMSE values of $0.53 \mathrm{~mm} /$ day, $0.54 \mathrm{~mm} /$ day, and $0.58 \mathrm{~mm} /$ day; and PBIAS values of $3.21 \%, 11.74 \%$, and $10.73 \%$ for SJW, GJW, and BJW, respectively. Graphical comparisons between observed data and calibrated result of YDD, DCD, SJW, GJW, and BJW are shown in Figure 5.

[Insert Table 2]

[Insert Table 3]

[Insert Figure 5]

\subsection{Hydrologic Responses to Groundwater Abstraction and Forest Growth}

Calibrated model ran 10-year hydrology of the target watershed. The condition of watershed hydrology was explained by hydrological components including evapotranspiration (ET), surface runoff (SR), percolation $(\mathrm{PE})$, soil moisture (SM), groundwater flow (GF), infiltration (IN), groundwater recharge (GWR), and lateral flow (LF).

The hydrologic components in the 1980s were used as a standard data to estimate hydrologic responses. Three scenarios were applied to understand how GA and FG separately and concurrently affected watershed hydrology. Scenario 1, 2, 3 considered decadal GA change (GA1990s, GA2000s, GA2010s), decadal FG change (FG1990s, FG2000s, FG2010s), and decadal change for both GA and FG (1990s, 2000s, 2010s), respectively. When estimating three scenarios, the decadal condition of GA and FG corresponding to each decade was applied to SWAT while weather condition was fixed on the 2010s so that the impact of two factors can be observed.

Based on the watershed hydrology estimated from the 1980s and three scenarios, the hydrologic responses were examined at the watershed outlet subbasin to understand the impact of GA and FG on the whole catchment. Table 4 summarized the hydrologic responses of the seven hydrological components and total runoff (TR) calculated from SR, FG, and LF. In GA scenario, GF has temporally decreased and GWR has temporally increased. Resultingly, TR has temporally decreased and showed the decrease percentage of $0.9 \%$ (7.0 mm/year), $3.1 \%$ (24.1 mm/year), and $5.8 \%$ (44.9 mm/year) in the GA1990s, the GA2000s, and 
the GA2010s, respectively. In FG scenario, the growth of forest has temporally increased ET with the value of $0.5 \%$ (2.9 mm/year), $1.5 \%$ ( $8.6 \mathrm{~mm} /$ year), $2.4 \%$ (13.4 mm/year) in the FG1990s, the FG2000s, and the FG2010s, respectively. Influenced by the increase of ET, other hydrological components showed decreasing trend which led to the temporal decrease of TR. TR in the FG scenario showed the decrease percentage of $0.4 \%$ (3.4 mm/year), $1.3 \%$ (10.4 mm/year), and 2.0\% (15.8 mm/year) in the FG1990s, the FG2000s, and the FG2010s, respectively. When both GA and FG were considered, the result showed decreasing trend of SR, PE, SM, GF, and LF while ET and GWR showed increasing trend. Consequently, TR was decreased by $1.3 \%$ (10.1 mm/year), $4.4 \%$ (34.2 mm/year), and $7.8 \%$ (60.3 mm/year) in the $1990 \mathrm{~s}$, the $2000 \mathrm{~s}$, and the 2010s, respectively.

\section{[Insert Table 4]}

From the hydrologic response at the watershed outlet, monthly response of hydrologic components to GA, and FG in the 2010s compared with the 1980s was estimated and presented in Figure 6. As a result, the hydrologic response of all components showed high value in June and July while GF showed the biggest hydrologic response with the average value of $25.61 \%$. The fluctuation of all hydrological beside GF showed a tendency to increase from January to June and decrease from June to December. In case of GF, although it showed same tendency that the decrease rate showed high value in June and July, there observed additional up and down tendency from October to March.

\section{[Insert Figure 6]}

To comprehend the impact of GA and FG on the annual streamflow condition, flow-duration curves of the 1980s and three scenarios were additionally analyzed. Using the descending order of streamflow data, the flow rate corresponding to the time duration of $90,180,275$, and 355 day was estimated. Table 5 showed the temporal reduction percentage of TR in different time durations compared with the 1980s. Q90, Q180, Q275, and Q355 stand for the flow rate according to the time duration of 90, 180, 275, and 355, respectively. From Table 5, two noticeable trends were observed. First, the reduction percentage has temporally increased in all scenarios. The reduction percentage in time duration of 355 in Scenario 3 showed $4.3 \%, 10.6 \%$, and $16.8 \%$ in the 1990s, 2000s, and 2010s, respectively. Secondly, the streamflow in bigger duration showed higher value of decrease percentage. In case of the 2010s in Scenario 3, the time duration of 90, 180, 275, and 355 showed $7.3 \%, 8.3 \%, 9.5 \%$, and $16.8 \%$ of reduction percentage, respectively. These two increasing trends were equally applied to all scenarios and time durations.

[Insert Table 5]

\subsection{Spatial Vulnerability of Total Runoff Decrease}

Based on the 78 subbasins delineated by SWAT, the spatial vulnerability of TR caused by GA and FG was observed using the decrease percentage of TR in each subbasin. The percentage was estimated from the TR difference of each subbasin between the 1980s and three scenarios. The results are presented in Figure 7. Commonly, the spatial vulnerability of TR loss has temporally intensified in all scenarios. In GA scenario, the maximum percentage of TR decrease in a subbasin reached $3.0 \%, 8.2 \%, 12.2 \%$ in the GA1990s, the GA2000s, and the GA2010s, respectively. In FG scenario, the percentage showed $1.6 \%, 4.4 \%$, and $6.3 \%$ in the FG1990s, the FG2000s, and the FG2010s, respectively. In Scenario 3, the percentage became 3.6\%, $10.3 \%$, and $14.9 \%$ in the $1990 \mathrm{~s}$, the $2000 \mathrm{~s}$, and the $2010 \mathrm{~s}$, respectively.

Spatially, the vulnerability distribution between GA and FG scenario was different. The decadal GA mainly influenced the downstream and West-Northern subbasins while that of FG imposed the decrease of TR mostly on the West-Northern subbasins. In Scenario 3, these vulnerabilities were spatially integrated and resultingly showed that the subbasins vulnerable to TR loss were prevalent along the downstream and West-Northern part of the target watershed.

[Insert Figure 7]

\section{DISCUSSION}


The long-term change of GA and FG in the target watershed affected the watershed hydrology and caused the spatial and temporal decrease of TR. The two factors showed different influence on the watershed hydrology. In case of the decadal change of GA, GF has temporally decreased and GWR has temporally increased while other hydrological components were unaffected. The increasing groundwater use has lowered groundwater level and forced the overlying saturated zone to fill up the deficit which consequently decreased GF and increased GWR. In the aspect of FG, the increase of ET, a natural result of the vegetation growth, is the initial point of hydrologic response. The increased ET led to the decrease of SR and the mass of water infiltrated into the soil layer. Lessened infiltration then reduced the underground components including LF, $\mathrm{PE}, \mathrm{GF}$, and GWR. The series of hydrologic response from decadal GA and FG decreased TR in the target watershed as a result.

The significant decrease rate of hydrologic components in June and July is a corresponding result to the climate characteristic of South Korea that shows concentrated rainfall in Summer. According to the concentration of rainfall, cultivation under structure and the growth of vegetation in South Korea are focused on Summer, and the decadal change of GA and FG indicated that the cultivation and growth have been temporally developed. Thus, the hydrological components showed bigger response during Summer. By the way, the additional trend from October to March discovered from the fluctuation of GF can be explained by water curtain cultivation. The cultivation, one of the farming methods utilized during dry period, uses pumped groundwater to reserve water supply and keep vinyl house warm. Regarding that water curtain cultivation is usually performed from October to March in South Korea, and the site of water curtain cultivation has been largely expanded for the past four decades (Chung and Chang, 2016), we can infer that the trend of GF came from water curtain cultivation.

The analysis on flow-duration curves suggested two noticeable trends in terms of the annual streamflow condition of the target watershed. One is the temporal decrease of streamflow which noted that the decadal change of GA and FG has consistently worsened the annual streamflow condition. Another trend is related to the flow rate in different time duration. The flow rate in bigger time duration showed higher value of decrease percentage which indicated that the influence of GA and FG on the streamflow loss became stronger in lower flow rate.

The spatial vulnerability of TR loss in GA scenario and FG scenario followed the spatial increment of groundwater use (Figure 3) and the distribution of forested area in the study area (Figure 1. (c)) which proves that the model simulation made a good agreement with the actual change of groundwater use and forest growth. The vulnerability of TR loss showed that the subbasins with small streams are more vulnerable to GA and FG due to their smaller flow rate so that tributaries and branches of mainstream are more vulnerable to stream drying phenomena. By the way, the spatial vulnerability in GA scenario showed higher degree of streamflow loss than FG scenario. The decadal record of groundwater use showed increase of $299.710^{6} \mathrm{~m}^{3}$ in the 2010s since the 1980s. From the record, agricultural use from groundwater showed the highest increase of $149.110^{6} \mathrm{~m}^{3}$ which accounts for $49.8 \%$ of the total increment. Furthermore, the monthly hydrologic responses graphically displayed that the GF in June and July has decreased the most due to the water use in farming season. As a result, it can be concluded that the agricultural water use from groundwater was the most influential factor that has decreased streamflow in the target watershed for the last four decades.

\section{CONCLUSIONS}

The long-term groundwater abstraction and forest growth impact on the watershed hydrology was evaluated using SWAT. Using groundwater use and forest growth database from 1976 to 2015 that are prepared in 10year interval (1980s;1976 1985, 1990s; 1986 1995, 2000s; 1996 2005, 2010s;2006 2015) as SWAT input data, SWAT was calibrated based on the daily observation data at two multipurpose dams and three multifunction weirs in the study area. Calibrated SWAT estimated the watershed hydrology of three scenarios in terms of hydrological components. The hydrologic response to GA and FG was measured by comparing estimated components.

The long-term change of GA and FG in the target watershed affected the watershed hydrology and caused 
the spatial and temporal decrease of TR. Temporally, the decrease of TR influenced by GA and FG showed $3.6 \%, 10.3 \%$, and $14.9 \%$ in the $1990 \mathrm{~s}$, the $2000 \mathrm{~s}$, and the $2010 \mathrm{~s}$, respectively. Spatially, the subbasins with small stream were appeared to be more vulnerable to the loss of streamflow. Furthermore, the analysis on flow-duration curve showed that the decadal change of GA and FG has consistently worsened the annual streamflow condition and their impact on the streamflow loss became stronger in lower flow rate.

The monthly analysis on the change of hydrological components explained that the decadal change of GA and FG mainly influenced the hydrological components in Summer due to the development of cultivation under structure and the vegetation growth while GF showed the biggest decrease. And decreasing GF in Winter came from water curtain cultivation expanded for the last four decades. By the way, GA showed bigger influence on the spatial vulnerability of TR loss than FG. Among three types of GA, agricultural use from groundwater showed the highest increase temporally and accordingly the fluctuation of GF in the monthly hydrologic response was biggest in Summer, farming season in South Korea. Therefore, we can infer that the agricultural water use pumped from groundwater use imposes the biggest impact on the stream drying in the Geum River basin.

In this study, groundwater abstraction and forest growth were selected as the stream drying factors that possibly influence the watershed hydrology. However, there are still many factors that are expected to affect the hydrology including land use change, road network development, and soil erosion. These factors have temporally developed like groundwater abstraction and forest growth. Thus, further studies on them are necessary to figure out comprehensive impact of stream drying factors on the watershed hydrology and to determine the priority of water resource management.

\section{ACKNOWLEDGEMENTS}

This paper was supported by Konkuk University in 2017.

\section{REFERENCES}

Birkinshaw, S.J., Bathurst, J.C. \& Robinson, M. (2014). 45 years of non-stationary hydrology over a forest plantation growth cycle, Coalburn catchment, Northern England. Journal of Hydrology. 519, 559-573.

Chung, I.M. \& Chang, S.W. (2016). Analysis and evaluation of hydrological components in a water curtain cultivation site. Journal of Korea Water Resoure Association. 49(9), 731-740.

Gleeson, T., VanderSteen, J., Sophocleous, M.A., Taniguchi, M., Alley, W.M., Allen, D.M. \& Zhou, Y. (2010). Groundwater sustainability strategies. Nature Geoscience. 3, 378-379.

Jung, C.G., Lee, J., Lee, Y. \& Kim, S. (2019). Quantification of stream drying phenomena using grid-based hydrological modeling via long-term data mining throughout South Korea including ungauged areas. Water. 11(3), 477.

Jung, C.G. \& Kim, S.J. (2017). Evaluation of land use change and groundwater use impact on stream drying phenomena using a grid-based continuous hydrologic model. Paddy Water Environment. 15(1), 111-122.

Kim, N.W., Lee, J., Lee, J.E. \& Won, Y.S. (2012). Development of relational formula between groundwater pumping rate and streamflow depletion. Journal of Korea Water Resource Association. 45(12), 1243-1258.

Kirk, S. \& Herbert, A.W. (2002). Assessing the impact of groundwater abstractions on river flows. Geological Society, London, Special Publications. 193(1), 211-233.

Lee, G., Shin, Y. \& Jung, Y. (2014). Development of web-based RECESS model for estimating baseflow using SWAT. Sustainability 6(4), 2357-2378.

Lee, J., Jung, C., Kim, S. \& Kim, S. (2019). Assessment of climate change impact on future groundwaterlevel behavior using SWAT groundwater-consumption function in Geum river basin of South Korea. Water. 11(5), 949 . 
Luo, Y., Arnold, J., Allen, P. \& Chen, X. (2012). Baseflow simulation using SWAT model in an inland river basin in Tianshan mountains, Northwest China. Hydrology and Eart System Sciences. 16(4), 1259-1267.

Mackay, D.S. \& Band, L.E. (1997). Forest ecosystem processes at the watershed scale: dynamic coupling of distributed hydrology and canopy growth. Hydrological Processes. 11(9), 1197-1217.

Neitsch, S.L., Arnold, J.G., Kiniry, J.R. \& Williams, J.R. (2005). Soil and Water Assessment Tool Theoretical Documentation. Version 2005. Springer, Berlin.

Park, G., Lee, H., Koo, M.H. \& Kim, Y. (2016). Strategies for an effective artificial recharge in alluvial stream-aquifer systems undergoing heavy seasonal pumping. Journal of the Geological Society of Korea. $52(3), 211-219$.

Shi, P., Chen, C., Srinivasan, R., Zhang, X., Cai, T., Fang, X., .., Li, Q. (2011). Evaluating the SWAT model for hydrological modeling in the Xixian watershed and a comparison with the XAJ model. Water Resources Management. 25(10), 2595-2612.

Wen, F. \& Chen, X. (2006). Evaluation of the impact of groundwater irrigation on streamflow in Nebraska. Journal of Hydrology. 327(3-4), 603-617.

Woo, S.Y., Jung, C.G., Lee, J.W. \& Kim, S.J. (2019). Evaluation of watershed scale aquatic ecosystem health by SWAT modeling and random forest technique. Sustainability. 11(12), 3397.

Yongwei, Y., Winsheng, W., Fang, Y. \& Jinyan, Z. (2013). Examination of the Quantitative Relationship between Vegetation Canopy Height and LAI. Advances in Meteorology. 6, 2013.

Yue, S. \& Hashino, M. (2004). Statistical interpretation of the impact of forest growth on streamflow of the Sameura basin, Japan. Environmental monitoring and assessment. 104(1), 369-384.

Zhang, X., Srinivasan, R., Arnold, J., Izaurralde, R.C. \& Bosch, D. (2011). Simultaneous calibration of surface flow and baseflow simulations: a revisit of the SWAT model calibration framework. Hydrological Processes. 25(14), 2313-2320.

\section{Hosted file}

Figure.pdf available at https://authorea.com/users/414400/articles/522436-assessment-oflong-term-groundwater-abstraction-and-forest-growth-impacts-on-watershed-hydrologyusing-swat

\section{Hosted file}

Table.pdf available at https://authorea.com/users/414400/articles/522436-assessment-of-longterm-groundwater-abstraction-and-forest-growth-impacts-on-watershed-hydrology-using-swat 